\title{
Favorable effects of left ventricular reconstruction in patients excluded from the Surgical Treatments for Ischemic Heart Failure (STICH) trial
}

\author{
Vincent Dor, MD, Filippo Civaia, MD, Clara Alexandrescu, MD, Michel Sabatier, MD, and \\ Françoise Montiglio, MD
}

\begin{abstract}
Objective: We sought to examine the hemodynamic effects at 1 month and 1 year of left ventricular reconstruction by means of endoventricular patch plasty for patients with acute or chronic, very severe post-myocardial infarction heart failure who would have been systematically excluded from the Surgical Treatments for Ischemic Heart Failure (STICH) trial.

Methods: From 2002 to May 2008, 274 patients underwent left ventricular reconstruction for post-myocardial infarction scarring; 117 of these patients would not have been eligible for the STICH trial. The pertinent criteria for exclusion included 12 patients with no coronary vessel suitable for coronary artery bypass grafting; 17 patients within a month of myocardial infarction, including 11 with acute heart failure ( 8 septal ruptures and 3 cases of ventricular tachycardia); 48 patients receiving intravenous inotropes, intra-aortic balloon pumping, or both; 15 patients with bifocal or posterior scarring; 4 patients scheduled for heart transplantation; and 21 patients meeting 5 other exclusion criteria. These patients (mean age, 64 years; age range, 34-83 years) preoperatively had a mean 49\% (range, 35\%-75\%) scarred left ventricular circumference, as determined by means of magnetic resonance imaging assessment. In the patients with chronic heart failure, the preoperative ejection fraction was $26 \% \pm 4 \%$ (range, $9 \%-34 \%$ ), the end-diastolic volume index was $130 \pm 43 \mathrm{~mL} / \mathrm{m}^{2}(\mathrm{range}, 62-343 \mathrm{~mL} /$ $\mathrm{m}^{2}$ ), and the end-systolic volume index was $95 \pm 37 \mathrm{~mL} / \mathrm{m}^{2}$ (range, $45-289 \mathrm{~mL} / \mathrm{m}^{2}$ ). Mitral regurgitation was mild to severe in 56 patients and associated with annular dilatation $(\geq 35 \mathrm{~mm})$ in 51 patients. A strategy of left ventricular reconstruction by means of endoventricular circular suturing and patching excluded the scarred left ventricular wall and was balloon sized to provide a diastolic volume of $50 \mathrm{~mL} / \mathrm{m}^{2}$. Circular patches were used for anteroseptoapical lesions, and triangular patches were used for posterior lesions. The mitral valve was repaired in 51 patients, and coronary revascularization was performed in 105 patients (arterial grafts in 95 and mixed in 12). Seventy-eight patients had endocardectomy, and cryotherapy was used in 39 patients for ventricular tachycardia.
\end{abstract}

Results: Four in-hospital and 2 delayed deaths occurred during the first year. In 101 patients with chronic heart failure, magnetic resonance imaging revealed that ejection fraction improved from $26 \% \pm 4 \%$ preoperatively to $40 \% \pm 8 \%$ at 1 month and $44 \% \pm 11 \%$ at 1 year postoperatively. At these same time points, the end-diastolic volume index was reduced from $130 \pm$ $43 \mathrm{~mL} / \mathrm{m}^{2}$ to $81 \pm 27$ and $82 \pm 25 \mathrm{~mL} / \mathrm{m}^{2}$, respectively, and the end-systolic volume index was reduced from $96 \pm 45 \mathrm{~mL} / \mathrm{m}^{2}$ to $50 \pm 21$ and $47 \pm 20 \mathrm{~mL} / \mathrm{m}^{2}$, respectively.

Conclusions: With minimal associated mortality, left ventricular reconstruction produces durable improvement in left ventricular function in patients with a large scarred ventricular wall. Considering that this patient cohort would have been systematically excluded from the STICH trial, care should be taken not to extrapolate that study's results too widely so as to inappropriately deny selected patients an effective treatment for ischemic cardiomyopathies with an injured ventricle. (J Thorac Cardiovasc Surg 2011;141:905-16)

\section{Supplemental material is available online.}

Video clip is available online.

From Centre Cardio-Thoracique de Monaco, Monte Carlo, Monaco.

Disclosures: Authors have nothing to disclose with regard to commercial support.

Read at the 90th Annual Meeting of The American Association for Thoracic Surgery, Toronto, Ontario, Canada, May 1-5, 2010.

Received for publication April 1, 2010; revisions received Oct 11, 2010; accepted for publication Oct 16, 2010.

Address for reprints: Vincent Dor, MD, Centre Cardi-Thoracique de Monaco, 11 bis, Avenue d'Ostende, Cedex, MC 98004 Monte Carlo, Monte Carlo, Monaco (E-mail: vdor@ccm.mc).

0022-5223/\$36.00

Copyright $(92011$ by The American Association for Thoracic Surgery doi:10.1016/j.jtcvs.2010.10.026
Earn CME credits at

http://cme.ctsnetjournals.org

The aim of this study is to show by means of hemodynamic data and left ventricular (LV) wall-motion analyses 1 month and 1 year after surgical intervention that in patients with ischemic cardiomyopathies (ICMs) with a widely scarred LV wall and distended viable myocardium caused by eccentric systolic motion, the exclusion of the scar by means of endoventricular patch plasty (EVPP) is followed by a stable regression of LV remodeling and restoration of normal concentric contraction of the LV wall surrounding the scarred area. The pathophysiologies leading to ICM are diverse and complex, including depressed but viable ischemic myocardium, stunned or hibernating muscle, and asynergic fibrous scarring. 


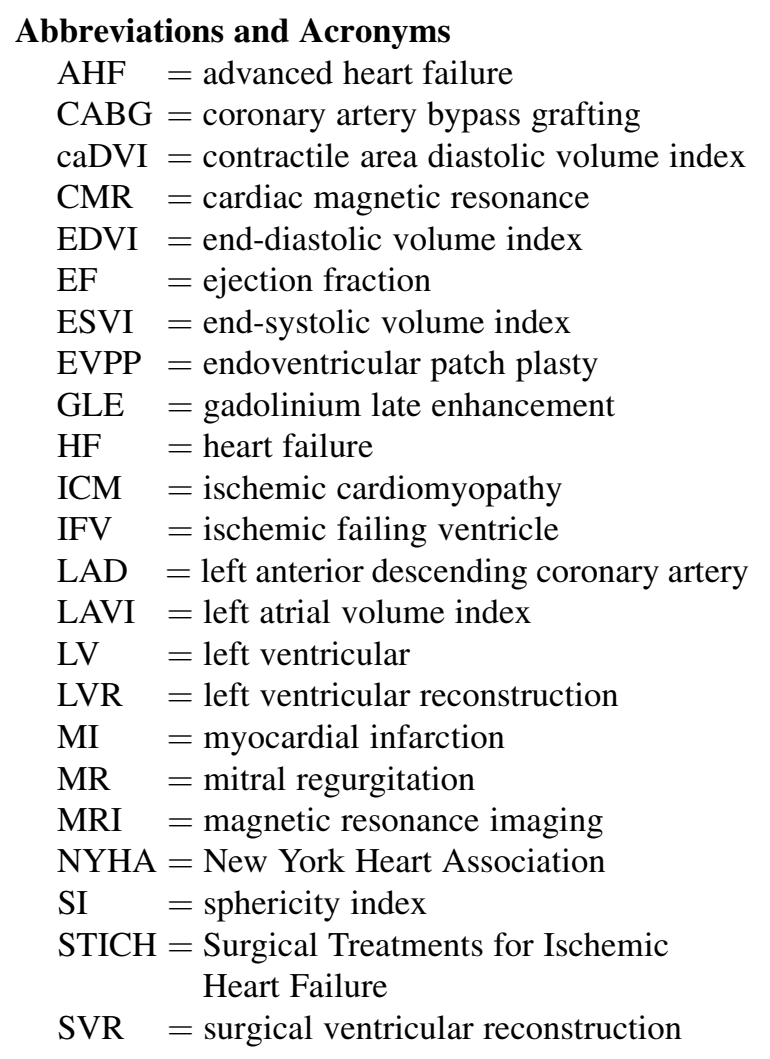

Although coronary artery bypass grafting (CABG) or percutaneous transluminal coronary intervention can treat ischemia, only left ventricular reconstruction (LVR) is specifically designed to address the scarring of the myocardial wall that triggers remote negative LV remodeling.

First demonstrated in 1967 by Klein and associates ${ }^{1}$ and confirmed by McKay and coworkers, ${ }^{2}$ irreversible heart failure (HF) occurs when post-myocardial infarction (MI) scar involves $20 \%$ of the LV area or $40 \%$ of its perimeter. Since 1967, knowledge of post-MI HF has been expanded by numerous studies showing that even after recanalization of the culprit artery at the acute phase of MI, the LV wall almost always becomes permanently scarred. In $80 \%$ to $100 \%$ of such cases, ${ }^{3}$ the scarred wall shows extension from $6 \%$ to $80 \%$. Twenty-seven percent of patients with restoration of Thrombolysis in Myocardial Infarction grade 3 flow after $\mathrm{MI}^{4}$ have LV dilatation with $\mathrm{HF}$, a finding that correlates with the conclusion of Gaudron and coworkers ${ }^{5}$ that at 18 months after MI, $20 \%$ of patients are in congestive HF.

Since 2002, our institutional assessment of the scarred left ventricle after MI (with or without successful coronary recanalization) has been conducted in 840 patients by means of magnetic resonance imaging (MRI). The extent of gadolinium late enhancement (GLE) in 4 planes (2- and 4-chamber views, LV outflow tract, and short axis at the level of the papillary muscle base) allowed us to build a GLE map with the percentage of scarred LV perimeter (Figure 1) that correlates to the classical centerline method. ${ }^{6}$ Ninety percent of patients have $10 \%$ or greater scarred LV perimeter (Figure 2), and $22 \%$ of these patients are in advanced HF (AHF), according to the criteria of the European Society of Cardiology, ${ }^{7}$ or in acute HF. AHF exceeds $53 \%$ for those patients with a scarred LV perimeter of greater than $50 \%$. The degree of AHF and the percentage of scarred circumference are more increased in those patients $(n=229)$ who had recanalization of an occluded coronary artery during the acute phase of MI (Figure E1, $A$ and $B$ ). Recanalization, per se, does not carry deleterious effects (unless performed too late in a totally necrotic territory initiating the "myocardial reperfusion induced injury" ${ }^{\prime}$ ) but emergency recanalization was applied to the sickest patients.

These highly scarred left ventricles in patients with chronic HF and New York Heart Association (NYHA) class III or IV, in those with AHF, or in those with acute HF are often beyond any response to medical treatment, to resynchronization, or to revascularization therapies. ${ }^{9}$ They represent ischemic failing ventricles (IFVs), the most severe category of ICM.

\section{MATERIALS AND METHODS}

From 2002 to May 2008, 274 patients after MI underwent LVR with EVPP at our institution . ${ }^{10}$ One hundred seventeen patients had LV scarring of greater than $35 \%$, (chronic NYHA class III/IV or acute HF) and met the exclusion criteria for the Surgical Treatments for Ischemic Heart Failure (STICH) trial, as listed in the "STICH investigator's handbook." The pertinent exclusion criteria are listed in Table 1.

All 117 patients had left and right heart catheterization, coronary angiography, and programmed ventricular stimulation to detect a potential ventricular arrhythmia induced by the scar. Asynergic scarring (dyskinetic or akinetic), systolic function (ejection fraction [EF], end-diastolic volume index [EDVI], and end-systolic volume index [ESVI]) and diastolic function (left atrial volume index [LAVI] $)^{11}$ were assessed by means of MRI to be more reliable. ${ }^{12}$ A GLE map was established for all patients with a 1.5-T imager (Siemens Sonata). For patients with intra-aortic balloon pumping or previous pacemaker or defibrillator implantation contraindicating MRI, the hemodynamic parameters were assessed by means of echocardiographic analysis, angiographic analysis, and computed tomographic scanning.

Table 2 shows the clinical characteristics and hemodynamic data for the 106 patients with chronic AHF and 11 patients with acute HF. Mitral insufficiency ( 56 patients) was quantified by using proximal isovelocity surface area, and the distribution of classification ${ }^{13}$ is also presented in Table 2.

The preoperative assessment confirmed the fact that the trigger of HF was a large scarred akinetic wall (mean, $49.5 \%$ of LV perimeter; range, $35 \%-75 \%$ ) and also that the mechanism that induces ventricular dilatation is (functionally but not histologically speaking) a deleterious systolic eccentric (centrifugal) motion (Figure E2 and Videos 1-3) of the noninfarcted myocardium surrounding the scar. This eccentric motion is best seen on MRI, immediately after MI, when the wall is still necrotic (no reflow or microvascular obstruction). The ongoing dilatation process is correlated to the amount of myocardial loss; it might take only a few weeks if this loss exceeds $50 \%$ of the left ventricle (evolving aneurysms) or up to months and years. This ineffective contraction is explained by "the extent of shortening of the remaining myocardium exceeding its physiological limits." 1 

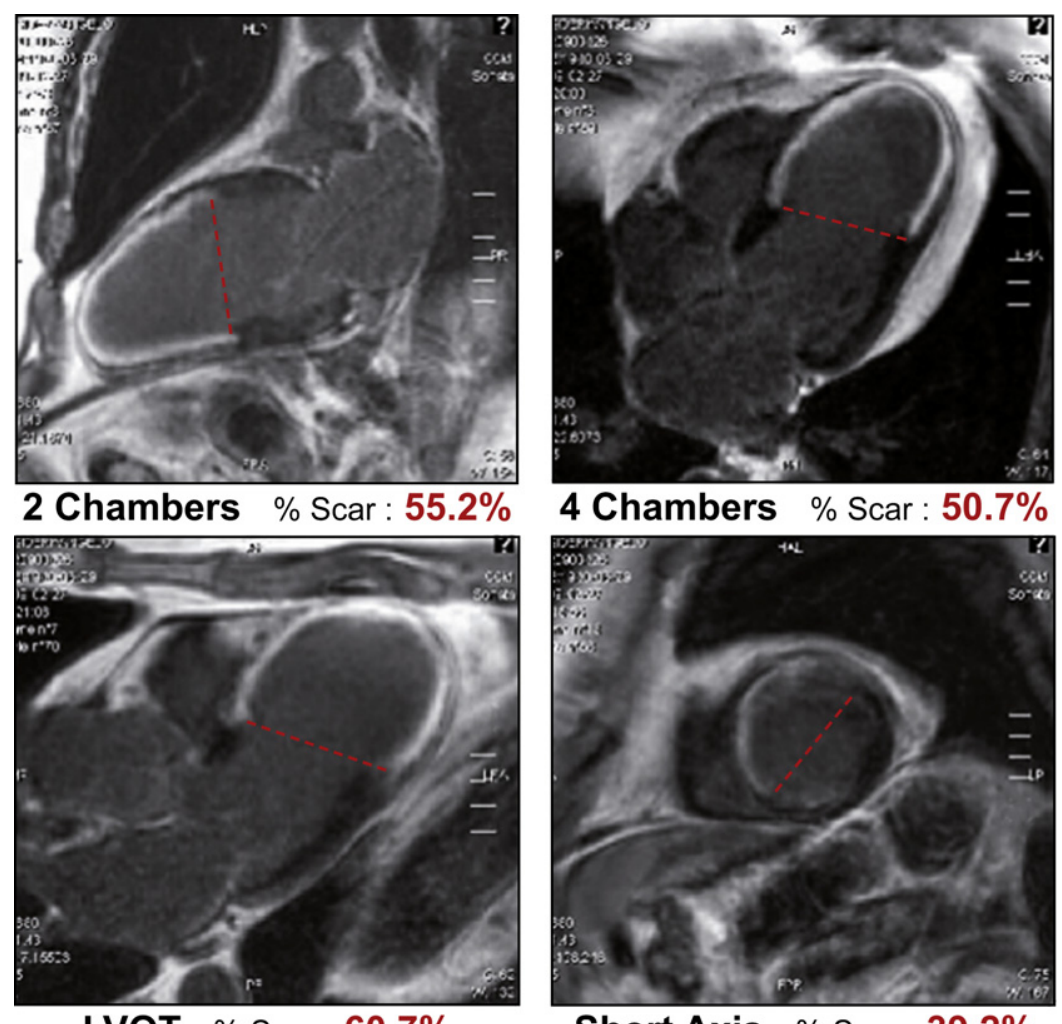

\begin{tabular}{|l|l|}
\hline EDVI & $140 \mathrm{ml} / \mathrm{m}^{2}$ \\
\hline ESVI & $99 \mathrm{ml} / \mathrm{m}^{2}$ \\
\hline E. F. & $29 \%$ \\
\hline LAVI & $73 \mathrm{ml} / \mathrm{m}^{2}$ \\
\hline
\end{tabular}

Short Axis \% Scar : $39.2 \%$

\section{Total Scar : $51,45 \%$}

\section{C.A.D.V.I $=140-140 \times 51,45 / 100=68 \mathrm{ml} / \mathrm{m}^{2}$}

FIGURE 1. Gadolinium late enhancement (GLE) map of an 85-year-old patient with previous obstruction and stenting of the left anterior descending coronary artery. The scar exceeded $50 \%$ of the left ventricular wall perimeter. LVOT, Left ventricular outflow tract; EDVI, end-diastolic volume index; ESVI, end-systolic volume index; E. F., ejection fraction; LAVI, left atrial volume index; C.A.D.V.I., contractile area diastolic volume index.

\section{Goals and Technique of LVR}

LVR by means of EVPP was proposed in $1984^{10}$ to rebuild from inside the left ventricle after a large blind endocardectomy, ${ }^{14}$ before the implantable defibrillator era, to treat intractable ventricular arrhythmias after MI. LVR is an etiological technique with the goals of exclusion of the scarred left ventricle, prevention of progressive dilation, and creation of an appropriate diastolic chamber size.

The feasibility of the ventricular reconstruction is based on the assessment of the theoretical contractile area diastolic volume index (caDVI; Figure 1) obtained by the subtraction from the global EDVI of one hundredth of the product EDVI multiplied by the mean percentage of scarred wall perimeter, as measured by using the GLE map. If the caDVI is greater than 45 to $50 \mathrm{~mL} / \mathrm{m}^{2}$, an efficient contractile cavity can be rebuilt irrespective of borderline severe cases with pulmonary hypertension, mitral regurgitation (MR), and renal failure. The correlation between the caDVI and the immediate postoperative EDVI is demonstrated in specific case examples (Figures 4, 5, E4, and E5, and Videos 6-15).

The LVR technique (Figure 3) comprises 4 elements: eliminating mitral insufficiency, achieving coronary revascularization, endocardectomy, and ventricular cavity remodeling. The complete technique is conducted on the arrested heart (crystalloid cardioplegia and continuous local cooling).

The majority of mitral repairs were accomplished by means of posterior annuloplasty (with a $6 / 7-\mathrm{cm}$ polytetrafluoroethylene strip) to treat dilatation greater than 35 to $38 \mathrm{~mm}$ in diameter. More rarely $(<5 \%)$, MR can be related to scarred papillary muscle or a displaced papillary muscle root. The situation then requires papillary muscle reimplantation or mitral replacement.

All suitable vessels for bypass on the noninfarcted area and also the infarcted vessel must be revascularized. With regard to the occluded left anterior descending coronary artery (LAD), we always try to bypass it, even if the run-off is not seen on the angiogram (but is visible on a computed tomographic scan). It must also be mentioned that patent LADs stented after recanalization are also bypassed as antiplatelet therapy is discontinued during the postoperative phase.

Endocardectomy is accomplished in a blind fashion with cryotherapy on the edge of the resection in patients when spontaneous or inducible ventricular tachycardia is detected during the preoperative assessments. ${ }^{15}$

The scarred LV wall is excluded by an endoventricular circumferential suture (Fontan technique), which is placed at the border between the scarred and normal myocardium. Placement can either be straightforward by following the delineated endocardial fibrous scar ("contractility trail"; Figure 3, $B$ ) or be guided by the GLE map when the endoventricular scar is not well delineated when patients undergo surgical intervention during the first weeks or months after MI.

LVR should maintain a normal diastolic volume to avoid an excessive volume reduction with its immediate (low cardiac output) or delayed (restrictive cardiomyopathy) consequences. This is accomplished by tying 


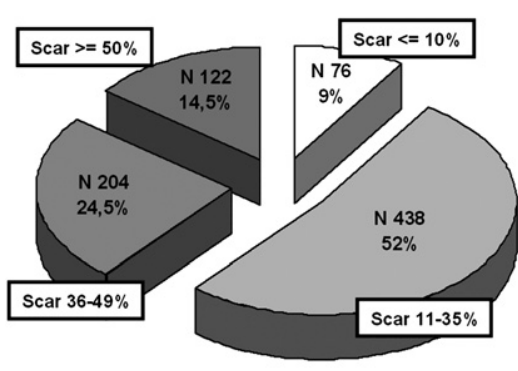

$\%$ of scared LV circumference in 840 patients

A

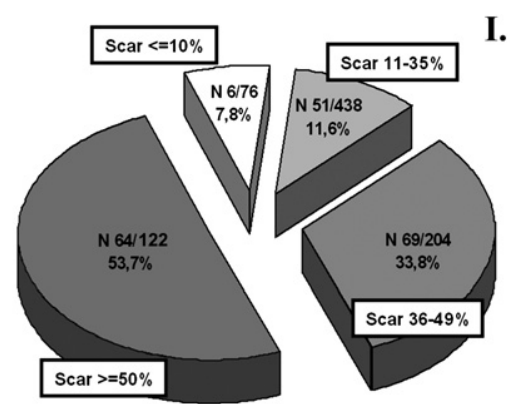

$\%$ of AHF

$\mathrm{N}=190 / 840$ patients $=\mathbf{2 2 . 6} \%$

B

FIGURE 2. Linear relationship of infarct size/degree of advanced heart failure (AHF) I ( 840 gadolinium late enhancement maps after myocardial infarction). A, Scar extension (percentage of the left ventricular $[L V]$ perimeter) in 840 patients after MI. B, percentage of AHF according to the percentage of scar extension.

the circumferential suture on a rubber balloon (Figure 3, C) inflated at the theoretical physiological diastolic volume of the patient (ie, approximately $50 \mathrm{~mL} / \mathrm{m}^{2}$ ). This diastolic volume balloon sizing, which has been used since $1998,{ }^{16}$ has changed the long-term results of LVR, avoiding the recurrence of remodeling noticed in our previous series ${ }^{17}$ and those of others. ${ }^{18}$

The closure of the rebuilt LV cavity is done with a patch tailored to the appropriate shape and size of the remaining orifice. This patch (Dacron, autologous pericardium, or, rarely, a piece of autologous fibrous endocardium with a septal hinge) is anchored on the "clothesline" of the endoventricular suture. Finally, the excluded fibrous areas are sutured above the patch, avoiding blockage of the revascularized coronary vessel or simply folded on the patch in case of very large exclusion of the septum to avoid plication of the septum and distortion of the right ventricular cavity.

\section{Concomitant Procedures (Table 3)}

CABG was performed in $105(89.7 \%)$ patients, with a mean number of 1.9 grafts. The LAD was grafted in 88 patients. Concomitant mitral valve repair or replacement was performed in 51 patients. This included annuloplasty $(\mathrm{n}=31)$, annuloplasty plus the edge-to-edge (Alfieri) technique $(\mathrm{n}=18$, totally discontinued since 2005 ), and valve replacement ( 1 for a lateral aneurysm and 1 for an anterior valve rupture after prior Alfieri repair).

EVPP can be applied in all types of scarred ventricles, most often for the anteroseptoapical region with an oval or circular patch but also for posterior, posteroseptal, posteroapical, and posterolateral asynergies with a triangular patch, with the basis attached on or near the mitral annulus to stabilize its geometry. The asynergy can be dyskinetic (transmural scar) or, more often, akinetic (subendocardial scar after coronary revascularization ${ }^{19}$ ). In this late circumstance the epicardial layer of myocardium covering the scar becomes progressively useless when the endocardial scar is rigidified by fibrosis and calcification, as reported by Bax and colleagues. ${ }^{20}$

LVR is efficient because the asynergic patch $\left(5\right.$ to $9 \mathrm{~cm}^{2}$ ) replaces an LV asynergic area of between 60 to $110 \mathrm{~cm}^{2}$ (assessed by the endocardial resection). The diameter of the patch represents less than $20 \%$ of the $\mathrm{LV}$ perimeter. With the patch anchored on the contractile myocardium, the deleterious eccentric systolic (centrifugal) motion is replaced by a physiological concentric systolic contraction (centrepital) (Figure E3 and Videos 4 and 5). This restoration of a normal contraction was demonstrated in $1995^{21}$ and $2004^{22}$ by studies showing normalization of the architecture of pressure-length loops in the remote area.

Figure 4 shows LVR for a large anteroseptoapical scar. Other locations are also shown in the Electronic Appendix. Posterior scarring (Figure E4 and Videos 7-12) is treated with a triangular patch. The base is sutured on the posterior mitral annulus, its external edge is set on the contractile lateral wall, its internal edge is set on the contractile septum, and its apex is set at the base of the papillary muscle. Thus the patch restores normal distance between the posterolateral papillary muscle and the septum. Figure E5 (Videos 12-15) also shows an anterior septal rupture that is excluded from the rebuilt LV cavity by a patch anchored above the necrotic anterior and septal walls, as published first in $1987 .{ }^{23}$ In such cases sutures set at the limit of necrotic tissues must be transmural and reinforced by Teflon felt.

\section{Statistical Analysis}

Data are expressed as medians \pm standard deviations. Repeatedmeasures analysis of variance was performed to analyze the ventricular indices. All analyses were performed with SPSS 17.0 software (SPS, Inc, Chicago, Ill). Mean preoperative hemodynamic values were recalculated in 101 patients (106 patients with chronic HF) surviving at 1 year.

TABLE 1. Categorization of patients by STICH trial exclusion criteria*

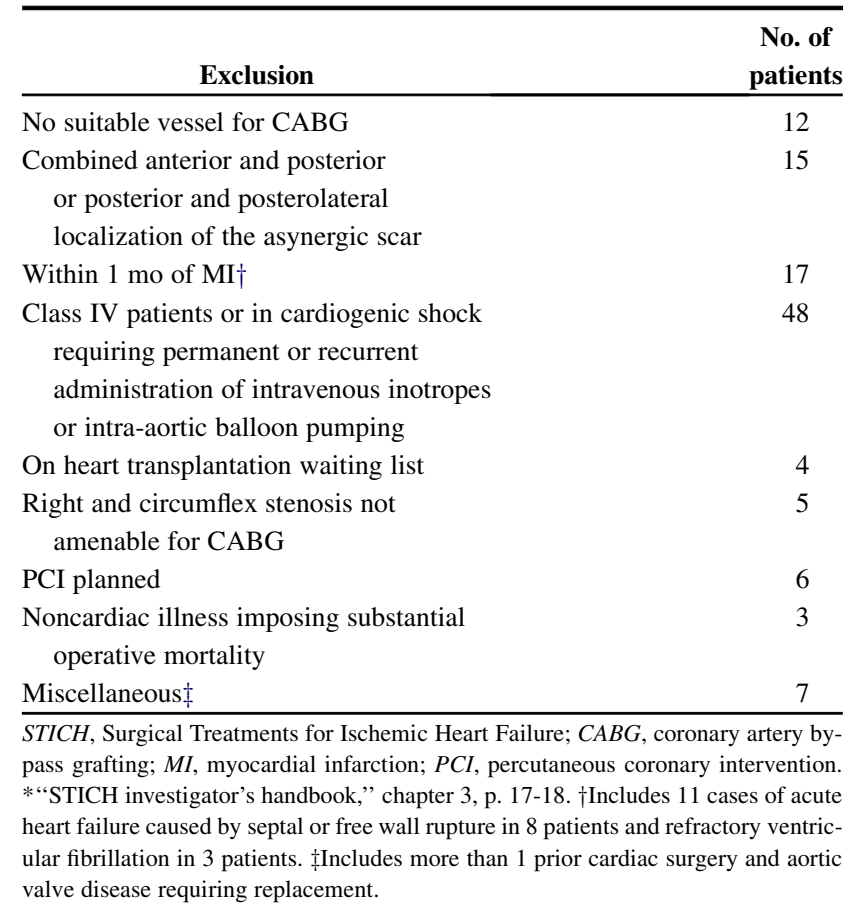


TABLE 2. Clinical and hemodynamic characteristics of 117 STICH trial noncandidates undergoing LVR

\begin{tabular}{llc}
\hline \multicolumn{1}{c}{ Characteristic } & \multicolumn{1}{c}{ Value } & Range \\
\hline Age $(\mathrm{y})$ & Mean $=64$ & $35-83$ \\
Age $>70 \mathrm{y}$ & $49(42 \%)$ patients & \\
Male sex & $90(76.9 \%)$ patients & \\
Prior PCI & $58(49.6 \%)$ patients & \\
Mitral regurgitation & & \\
$\quad$ Mild $\left(\right.$ EROA $\left.<0.2 \mathrm{~cm}^{2}\right)$ & $17(14.5 \%)$ patients & \\
$\quad$ Moderate to severe & $49(41.9 \%)$ patients & \\
$\quad \quad \quad$ EROA $\left.>0.2 \mathrm{~cm}^{2}\right)$ & & $17-83$ \\
Pulmonary pressure $(\mathrm{mm} \mathrm{Hg})$ & Mean $=37$ & \\
Ventricular tachycardia present & $39(34.5 \%)$ patients & \\
$\quad$ or inducible* & & $9 \%-34 \%$ \\
EF $\quad$ & & \\
$\quad$ In 106 patients with chronic & $26 \% \pm 4 \%$ & $32 \%-50 \%$ \\
$\quad$ heart failure & & $62-343$ \\
$\quad$ In 11 patients with acute & $41 \% \pm 6.7 \%$ & $45-289$ \\
$\quad$ heart failure & & $17-94$ \\
EDVI $\left(\mathrm{mL} / \mathrm{m}^{2}\right), \mathrm{n}=106$ & $130 \pm 43$ & $35-77$ \\
ESVI $\left(\mathrm{mL} / \mathrm{m}^{2}\right), \mathrm{n}=106$ & $95 \pm 37$ & \\
LAVI $\left(\mathrm{mL} / \mathrm{m}^{2}\right), \mathrm{n}=55$ & $51 \pm 19$ & \\
GLE $(\%$ of scarred LV & & \\
perimeter $)$ & & \\
\hline
\end{tabular}

STICH, Surgical Treatments for Ischemic Heart Failure; $L V R$, left ventricular reconstruction; $P C I$, percutaneous coronary intervention; $E F$, ejection fraction; $E D V I$, end-diastolic volume index; $E S V I$, end-systolic volume index; $L A V I$, left atrial volume index; $G L E$, gadolinium late enhancement; $L V$, left ventricular. *Evaluated in 113 patients.

\section{RESULTS}

Survival

Overall hospital mortality for all patients undergoing EVPP (2002-2008) was 2.2\% (6/274) and 1.3\% (2/157) in patients "suitable" based on the STICH criteria. In the patient cohort meeting the STICH exclusionary criteria, mortality was $3.4 \%$ (4/117). In this last series 8 surviving patients were considered as not improved ("disappointing results") with persistent HF of NYHA class II/III, EF improvement of less than $5 \%$ to $7 \%$, and a dilated left ventricle (ESVI, $>60 \mathrm{~mL} / \mathrm{m}^{2}$ ), with numerous hospital readmissions and 2 late deaths during the first year.

At 1 year in the 51 patients undergoing mitral surgery, there were 2 prostheses with normal function, no MR in 16 patients, mild MR in 28 patients, and moderate MR in 5 patients. The Kaplan-Meier survival curve (Figure 5) shows a rate at 8 years of greater than $80 \%$ (complete follow-up on 109/111 patients). Hospital readmission of these patients for complete hemodynamic and electrophysiological assessment was systematically proposed 1 month, 1 year, and 3 years after surgical intervention.

\section{Changes in Cardiac Function}

Table 4 details the hemodynamic results after 1 month and more than 1 year in the 111 survivors. The improvement in LV systolic function is progressive from 1 month to 1 year based on EF increase, from $26 \%$ before LVR up to $40 \%$ (statistically significant) and $44 \%$, respectively, and on ESVI, which decreased from $96 \mathrm{~mL} / \mathrm{m}^{2}$ to $50 \mathrm{~mL} / \mathrm{m}^{2}$ (statistically significant) and $47 \mathrm{~mL} / \mathrm{m}^{2}$, respectively. The improvement in diastolic function is characterized by the decrease in LAVI ( $\mathrm{n}=55$ patients $)$ from $51 \pm 19$ to $39 \pm$ $14 \mathrm{~mL} / \mathrm{m}^{2}$ ( $P=.001$, paired test). In the group of patients with acute HF, the encouraging result is obtained by the decrease in pulmonary hypertension from 62 to $38 \mathrm{~mm} \mathrm{Hg}$ $(P=.001$, paired test $)$ and the fact that almost normal values in terms of ESVI $(34 \mathrm{~mL})$ and EDVI $(67 \mathrm{~mL})$ are also obtained after 1 year $(P=.01)$.

Figures 4, 6, E3, and E4 (Videos 4-11) show the evolution after 1 year of the progressive and durable regression of the remodeling, in contrast with the 5 patients illustrating this article. This progressive and durable regression of the remodeling, in contrast to results seen in other publications, ${ }^{24,25}$ is explained by the abolition of the deleterious eccentric systolic motion with restoration of systolic concentric contraction of the viable myocardium and the maintenance of a physiological diastolic capacity by the diastolic volume balloon sizing. The rebuilt contractile LV cavity in the postoperative period can be spherical or elliptic: the sphericity index (SI) analysis shows more often an increase in SI at 1 month compared with the preoperative value but a return to preoperative values at 1 year and to a normal SI value $(\approx 0.30)$ at 3 years (Figures 4,6 , and E3, and Videos 4 and 5). This return to an elliptic shape is not imposed by a shaper but linked to physiological contraction of the LV cavity, irrespective of its immediate postoperative morphology.

\section{DISCUSSION}

The results presented here for LVR in cases of severe IFV speak for themselves. However, the recent report by Jones and colleagues ${ }^{26}$ has raised serious questions with regard to the effectiveness of this procedure and its value for all patients with ischemic HF. Because this report focuses on excluded STICH patients, it presents the opportunity to provide contrast and delineate any undermining pitfalls in the conduct and execution of the STICH trial.

In all types of HF (which is not an entity but a status in the evolution of all cardiomyopathies), the first duty is to carry out an efficient and reliable screening of the cause to undertake, if possible, an etiological adapted therapy. In patients with ICMs, the screening must determine whether the reason why the heart is failing is linked with the myocardial ischemia or is a consequence of myocardial necrosis. STICH criterion number 1 (ie, "coronary vessel suitable for CABG and limited anterior wall asynergia" not precisely assessed) addresses almost only the first cause of ischemic HF. This is confirmed by the preoperative assessments of the 1,000 patients in arm 2 (57 in NYHA class IV) with analysis of the Canadian Cardiovascular Society score but no assessment 


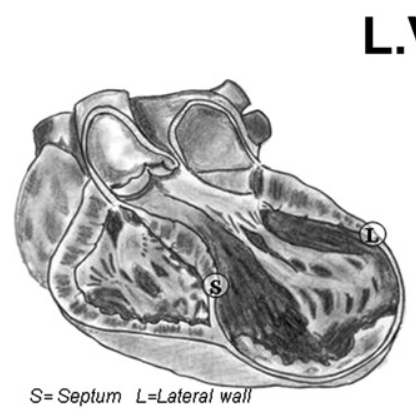

A Antero Septo Apical Aneurysm

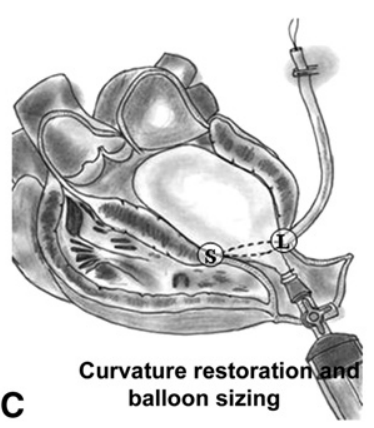

FIGURE 3. Left ventricular reconstruction (L.V.R.) by means of endoventricular circular patch plasty for postinfarction anteroseptoapical aneurysm. A, Scarred wall affects more than $50 \%$ of the left ventricular circumference. Contractile myocardium on the septum and lateral wall remote from the scar is distended by eccentric motion. B, The endoventricular purse-string suture (Fontan "trick") is set at the limit between the contractile and scarred wall, excluding all asynergic nonresectable areas. This "contractility trail" is easily seen when endocardial scar is fibrotic or calcified (years after infarction) or guided by the gadolinium late enhancement map in a recent infarct. $\mathrm{C}$, An endoventricular suture that restores the normal curvature and concentric contraction of the contractile myocardium is tied on a rubber balloon inflated at the normal diastolic volume $\left(50 \mathrm{~mL} / \mathrm{m}^{2}\right)$, avoiding low cardiac output or delayed remodeling recurrence. D, Once tied, the suture gives shape and size on the patch, which is anchored on this "clothesline," maintaining the myocardial circular reorganization.

of MR, pulmonary pressures, ventricular arrhythmias, and diastolic function, all markers of HF. It is also surprising that in neither the "STICH investigator's handbook" nor in the published results ${ }^{26}$ is there any definition or description of the surgical technique of surgical ventricular reconstruction (SVR). The only reference is the following: "certification of surgeon for performing SVR required evidence of consistent [sic] post operative decrease in LV volume in 5 consecutive surviving patients." There is no mention of the value or percentage volume reduction that a certified surgeon must be able to achieve. The 4-month analysis (performed by using echocardiographic analysis on only one third of the series) demonstrated an ESVI decrease of from 82 to $77 \mathrm{~mL} / \mathrm{m}^{2}(6 \%)$ in the CABG group, as opposed to 83 to $67 \mathrm{~mL} / \mathrm{m}^{2}(19 \%)$ in the SVR group.

The complementary information about the STICH trial presented by Michler at the American College of
Cardiology in 2010 is based on 595 patients among the 1,000 patients of arm 2 (405 being excluded for death 86, or lack of baseline studies!). In the group with a large left ventricle (ESVI $>90 \mathrm{~mL} / \mathrm{m}^{2}$ ), for the 117 patients with CABG plus SVR, $56 \%$ of them continue to have a dilated left ventricle (ESVI $>60 \mathrm{~mL}$ ), and EF increased from $21 \%$ to $27 \%$; for the 118 patients with CABG alone, $76 \%$ continue to have a large left ventricle, and EF increased from $22 \%$ to $25 \%$. These ESVI values of greater than the threshold of $60 \mathrm{~mL} / \mathrm{m}^{2}$ reflect poor prognosis, ${ }^{27}$ and these results contrast with those of our series, in which early ESVI decreased from 96 to $50 \mathrm{~mL} / \mathrm{m}^{2}(44 \%)$ and there was an increase in EF from $26 \%$ to $44 \%$ at 1 year. Thus these very limited improvements in ESVI and EF in the STICH trial might be misleading because SVR in this trial shows similar results to those of classical resection of an apical aneurysm followed by linear suturing, overlapping, or plicature, as described by Cooley and associates in $1958^{28}$ and by Stoney and coworkers ${ }^{29}$ and criticized by Froehlich and Falsetti ${ }^{30}$ (analyzing 6 postoperative angiograms after 18 anterior wall resections) as inefficient on LV performance.

Our precise methodology for viability and scar evaluation provides a benchmark for LVR preoperative evaluation and feasibility and contrasts starkly with what was attempted by the STICH trial, whereas the original protocol required greater than $35 \%$ asynergia from the anterior wall and an ESVI of greater than $60 \mathrm{~mL} / \mathrm{m}^{2}$; subsequent changes to the protocol dropped these requirements ${ }^{31}$ : "the presence or absence of myocardial viability in the dysfunctional anterior apical segment was not an enrollment criterion." Indeed, only $38 \%$ of STICH participants had any form of volume measurement, and $13 \%$ had no MI. ${ }^{31}$ It is therefore unreasonable and impossible to draw any broad conclusions from the STICH trial based on its patient evaluation methods, selection criterion, and final assessment on less than $60 \%$ of the enrolled patients.

It seems unrealistic to retrospectively or prospectively compare the long-term results of coronary revascularization, mitral repair, ventricular reconstruction, or even heart replacement for ICMs when the precise pathophysiology is not assessed. A large area of ischemic but viable myocardium requires $\mathrm{CABG}$, as opposed to a large irreversibly scarred wall, which requires ventricular surgery. We strongly object that revascularization can affect a scarred myocardium, especially when it involves $40 \%$ or more of the perimeter of the failing ventricle: this is what LVR is intended to treat, and it was never proposed as a necessary technique for a limited anteroapical bulging aneurysm. ${ }^{10,15-17}$ In the recent survey from the Cleveland Clinic $^{32}$ of 4 types of treatment in 1,468 patients with ICMs over 8 years, the authors did not find any long-term survival difference between CABG alone and CABG plus SVR (not precisely defined). But the authors mentioned that "The decision to pursue SVR includes MRI studies, viability, and the final inspection 

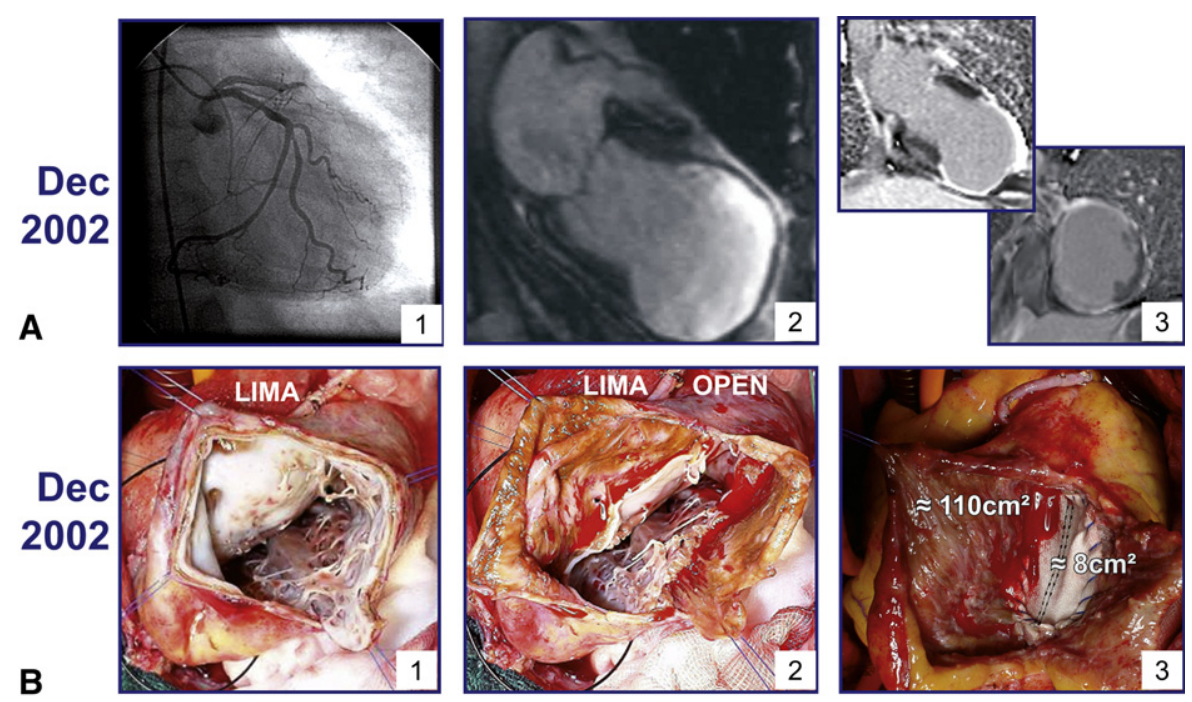

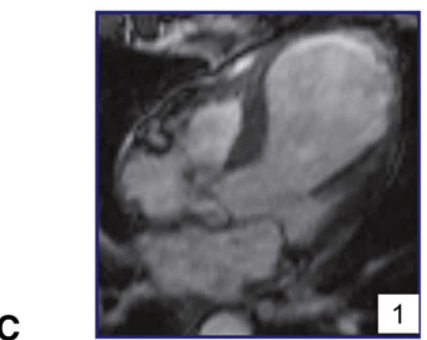

Dec. 2002

EDVI : $121 \mathrm{ml} / \mathrm{m}^{2}$

ESVI : $95 \mathrm{ml} / \mathrm{m}^{2}$

LVEF : $22 \%$

caDVI : $48 \mathrm{~m}$

LAVI : $50,8 \mathrm{ml} / \mathrm{m}^{2}$

SI : 0,42

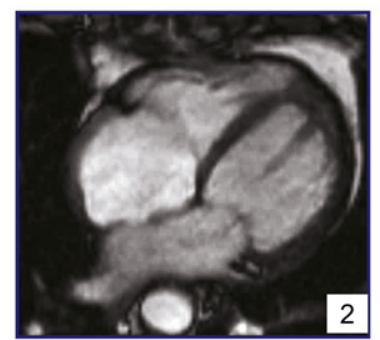

June 2004

EDVI : $54 \mathrm{ml} / \mathrm{m}^{2}$

ESVI : $25 \mathrm{ml} / \mathrm{m}^{2}$

LVEF : $53 \%$

LAVI : $41,5 \mathrm{ml} / \mathrm{m}^{2}$

SI : 0,59

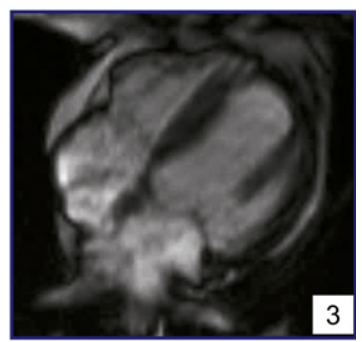

Oct. 2007 (87 y. !)

EDVI : $44 \mathrm{ml} / \mathrm{m}^{2}$

ESVI : $20 \mathrm{ml} / \mathrm{m}^{2}$

LVEF : $54 \%$

LAVI : $39 \mathrm{ml} / \mathrm{m}^{2}$

SI : 0,48

FIGURE 4. Anteroseptoapical large aneurysm: "compassionate" left ventricular reconstruction indication in an 82-year-old patient with drug-resistant congestive heart failure in New York Heart Association class IV+. A1, Preoperative coronary angiogram. A2, Two-chamber view. A3, Gadolinium late enhancement on the 4 scarred left ventricular walls (only papillary muscle roots and the lateral wall are not scarred). B1, Endocardial scar. The left internal thoracic artery (LIMA) was already implanted on the thrombosed left anterior descending coronary artery. $B 2$, After endocardectomy $\left(90 \mathrm{~cm}^{2}\right)$, bleeding occurring when the left internal thoracic artery is unclamped helps to determine the limit of the resection. B3, Endoventricular reconstruction excluding half of the anterior wall, two thirds of the interventricular septum, and one third of the posterior wall by using an 8 - $\mathrm{cm}^{2}$ patch. $C 1$, Preoperative 4-chamber view with a sphericity index (SI) of 0.42. C2, Postoperative 4-chamber view 1 month after left ventricular reconstruction with an SI of 0.59. C3, Postoperative 4-chamber view at 5 years after left ventricular reconstruction with an SI of 0.48. EDVI, End-diastolic volume index; ESVI, end-systolic volume index; $L V E F$, left ventricular ejection fraction; $c a D V I$, contractile area diastolic volume index; $L A V I$, left atrial volume index.

in the operating room, some factors that we did not and cannot incorporate in our (statistical) model." Again, without a framework of precise scar and volumetric analysis, the study's conclusions become severely weakened and irrelevant. In their discussion, the authors recall the point made earlier by Burkhoff and Weschler ${ }^{33}$ that "reducing ventricular size to improve systolic function makes sense, but (the) modeling data suggests the equal possibility of worsening ventricular diastolic function." This might have been a possibility in early series of LVR without diastolic volume balloon sizing ${ }^{24,25}$ but not in our series, in which diastolic function improved concomitantly with systolic function, as shown by the decrease in LAVI, which is the best witness to the decrease in diastolic burden. ${ }^{11}$
With regard to $M R$, it is surprising to see the number of contradictory publications ${ }^{34-36}$ of the various techniques and unsatisfactory long-term results. All these studies are undermined by the basic fact that ischemic MR is not a valvular but a ventricular disease. When MR is due to mitral annular dilatation, it can be repaired by means of posterior annuloplasty alone, and when it is related to a scarred lateral wall, papillary muscle displacement, or both, MR is treated by means of restoration of papillary muscle location or valve replacement. The stability of this repair is not linked to the technique itself but to the concomitant repair of the cause, mainly ventricular dilatation (ie, the exclusion of scarred asynergic areas and restoration of concentric systolic contraction). 


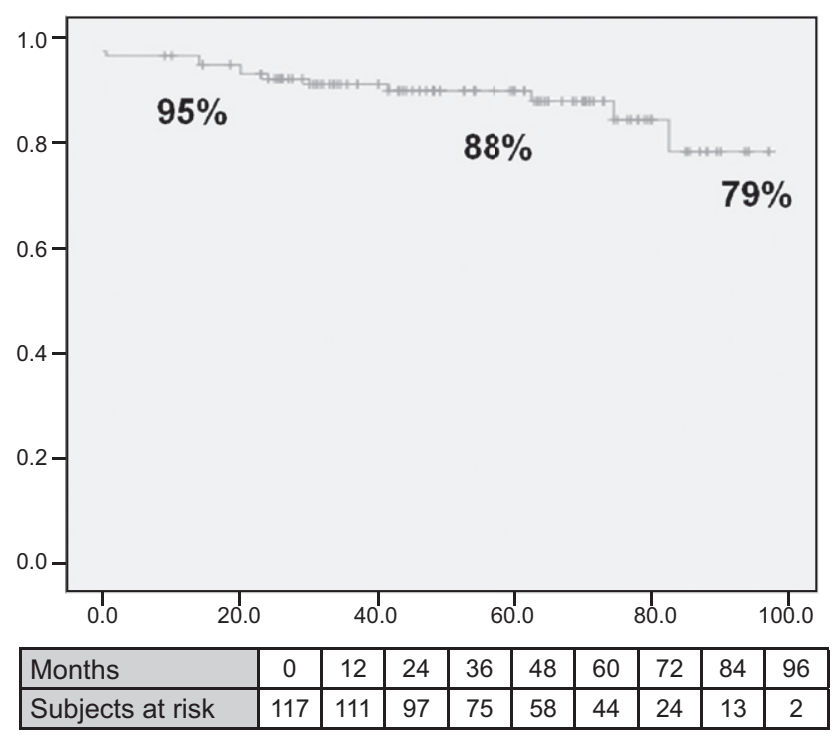

FIGURE 5. Kaplan-Meier survival curve on 111 ischemic failing ventricle $(I F V)$ survivors 1 year after left ventricular reconstruction $(L V R)$.

Because all 117 patients in our series would have been excluded from the STICH trial, the key issue is not to offer such patients either CABG, CABG plus SVR, or medical therapies that have already failed but whether they should undergo ventricular reconstruction or should be considered for heart replacement. Different factors need to be taken into consideration. Patients older than 70 years $(42 \%$ in this series) are excluded from heart transplantation programs. The results of an LV assist device in patients with such end-stage ischemic HF (REMATCH Trial) ${ }^{37}$ are not in favor of this last technique compared with the results of LVR. Finally, indications or contraindications for reconstructive surgery (LVR)

TABLE 3. Surgical techniques applied in 117 patients

\begin{tabular}{ll}
\hline \multicolumn{1}{c}{ Procedure } & \\
\hline Mitral valve surgery & 51 patients \\
Posterior annuloplasty & 31 patients \\
Id + edge-to-edge mitral repair & 18 patients \\
Mitral valve replacement (primary) & 1 patient \\
Mitral valve replacement (after failure & 1 patient \\
$\quad$ of edge-to-edge repair) & \\
Coronary revascularization & 105 patients \\
Arterial revascularization only & 2 patients \\
Venous graft only & $1.9 \pm 0.8$ (mean) \\
No. of distal anastomoses & \\
Ventricular reconstruction & 78 patients \\
Endocardectomy & 39 patients \\
Cryotherapy & 117 patients \\
Endoventricular patch & 108 patients \\
Dacron patch & 9 patients \\
Pericardium & 2 patients \\
Septal hinge & $102 \pm 35$ \\
Cardiopulmonary bypass time (min) & $74 \pm 23$ \\
Aortic crossclamp time (min) &
\end{tabular}

are not based on age or on the degree of severity of HF, pulmonary hypertension, or MR or the need for intravenous inotropes or intra-aortic balloon pumping but only on the anatomic possibility of rebuilding a contractile LV cavity with a physiological diastolic capacity.

Figure 6 shows the interest in analyzing the theoretical caDVI value in the end-stage ischemic ventricle in a hopeless situation. A 75-year-old patient was stented on the LAD on day 6 after the onset of acute MI with immediate stent thrombosis. Three months later, he experienced intractable HF. He was bedridden in the intensive care unit, undergoing dobutamine infusion and with pulmonary edema. His pulmonary artery pressure was $70 \mathrm{~mm} \mathrm{Hg}$, and he showed grade 2+ MR. At MRI assessment, EF was 9\%, ESVI was $289 \mathrm{~mL} / \mathrm{m}^{2}$, EDVI was $320 \mathrm{~mL} / \mathrm{m}^{2}$, and the mean scarred perimeter was $77 \%$. On GLE analysis the caDVI was 70 $\mathrm{mL} / \mathrm{m}^{2}$. He was therefore suitable for surgical intervention. Postoperative assessment showed an EDVI of $76 \mathrm{~mL} / \mathrm{m}^{2}$, as reliably predicted by the caDVI. The patient was controlled at 1 month and 1 year with progressive improvement and almost normal hemodynamic values. This case, as with 4 others on an active heart transplantation waiting list and alive and well 8, 7, 4, and 3 years, respectively, after LVR, leads us to believe that with regard to ICMs, indications for heart transplantation should be revised.

\section{Limitations}

The hemodynamic evolution of this series is an observational study without a control group because patients in end-stage chronic HF of NYHA class III or IV, despite full medical or resynchronization therapy, who are already revascularized on the culprit artery by means of PCI or surgical intervention, are bedridden, and are receiving intravenous dobutamine or intra-aortic balloon pumping cannot be reasonably proposed for other conservative therapies that already failed. The single alternative is heart transplantation, and for patients in acute HF with septal rupture or who are intractable ventricular arrhythmia defibrillator resistant and require rescue surgery, a randomized trial of $\mathrm{CABG}$ alone or medical treatment will never be proposed. It will only be through the rigorous examination of observational clinical datasets, such as ours, that the effect of LVR will be measured.

\section{CONCLUSIONS}

Based on more than 1,300 LVR operations in the last 25 years, we believe that this etiological conservative surgical technique suppresses the cause and the mechanism of the IFV by means of endoventricular exclusion of the scarred wall and restoration of concentric contraction of the viable myocardium. In the end-stage situation of an IFV with an asynergic scar of greater than $40 \%$ of the LV perimeter, LVR, with an operative risk of less than $10 \%$ and an improvement at 1 year in more than $80 \%$ of survivors, is a therapeutic option superior to other therapeutics 
TABLE 4. LV function in 111 patients surviving 1 year after LVR

\begin{tabular}{|c|c|c|c|c|}
\hline & EF $(\%)$ & $\operatorname{EDV}\left(\mathbf{m L} / \mathbf{m}^{2}\right)$ & $\operatorname{ESV}\left(\mathbf{m L} / \mathbf{m}^{2}\right)$ & $\operatorname{LAV}\left(\mathrm{mL} / \mathrm{m}^{2}\right), \mathbf{n}=\mathbf{5 5}$ \\
\hline \multicolumn{5}{|c|}{ Chronic HF $(\mathrm{n}=101)$} \\
\hline Preoperative & $26 \pm 4(9-34)$ & $130 \pm 43(62-343)$ & $96 \pm 45(45-289)$ & $51 \pm 19(17-94)$ \\
\hline $1 \mathrm{mo}$ & $40 \pm 8(21-64)^{*}$ & $81 \pm 27(46-170)^{*}$ & $50 \pm 21(24-118)^{*}$ & $39 \pm 14(13-72) \S$ \\
\hline \multirow[t]{2}{*}{$1 \mathrm{y}$} & $44 \pm 11(20-69)^{*}$ & $82 \pm 25(33-217)^{*}$ & $47 \pm 20(15-128) \dagger$ & NA \\
\hline & EF $(\%)$ & $\operatorname{EDV}\left(\mathrm{mL} / \mathrm{m}^{2}\right)$ & $\operatorname{ESV}\left(\mathbf{m L} / \mathrm{m}^{2}\right)$ & PAP (mm Hg) \\
\hline \multicolumn{5}{|c|}{ Acute $\mathrm{HF}(\mathrm{n}=10)$} \\
\hline Preoperative & $41 \pm 6(32-50)$ & $80 \pm 23(54-122)$ & $48 \pm 18(31-83)$ & $62 \pm 18(38-85)$ \\
\hline$>1 \mathrm{mo}$ & $51 \pm 11(38-68) \dagger$ & $52 \pm 18(28-79) \ddagger$ & $27 \pm 13(16-49) \ddagger$ & $38 \pm 8(30-49)$ \\
\hline$>1 \mathrm{y}$ & $54 \pm 12(38-72) \dagger$ & $67 \pm 25(32-105) \ddagger$ & $34 \pm 18(9-66) \ddagger$ & NA \\
\hline
\end{tabular}

$L V$, Left ventricular; $L V R$, left ventricular reconstruction; $H F$, heart failure; $E F$, ejection fraction; $E D V$, end-diastolic volume; $E S V$, end-systolic volume; $L A V$, left atrial volume; $P A P$, pulmonary artery pressure. $* P<.001$, effect of time, repeated-measures analysis of variance. $\dagger P<.01$, effect of time, repeated-measures analysis of variance. $\ddagger P=.01$, effect of time, repeated-measures analysis of variance. $\S P=.001$, paired $t$ test.

offered to such sick patients because LVR addresses the cause of the disease when other therapies try to palliate partially the consequences.

The conclusion of the STICH trial (biased by its selection and questionable results) on surgical treatment of
ICM is that " $[\mathrm{t}]$ here was no significant difference between $\mathrm{CABG}$ alone and $\mathrm{CABG}$ plus surgical ventricular reconstruction," and is thus unfounded and inappropriate for a large number of patients with severe ischemic congestive HF.

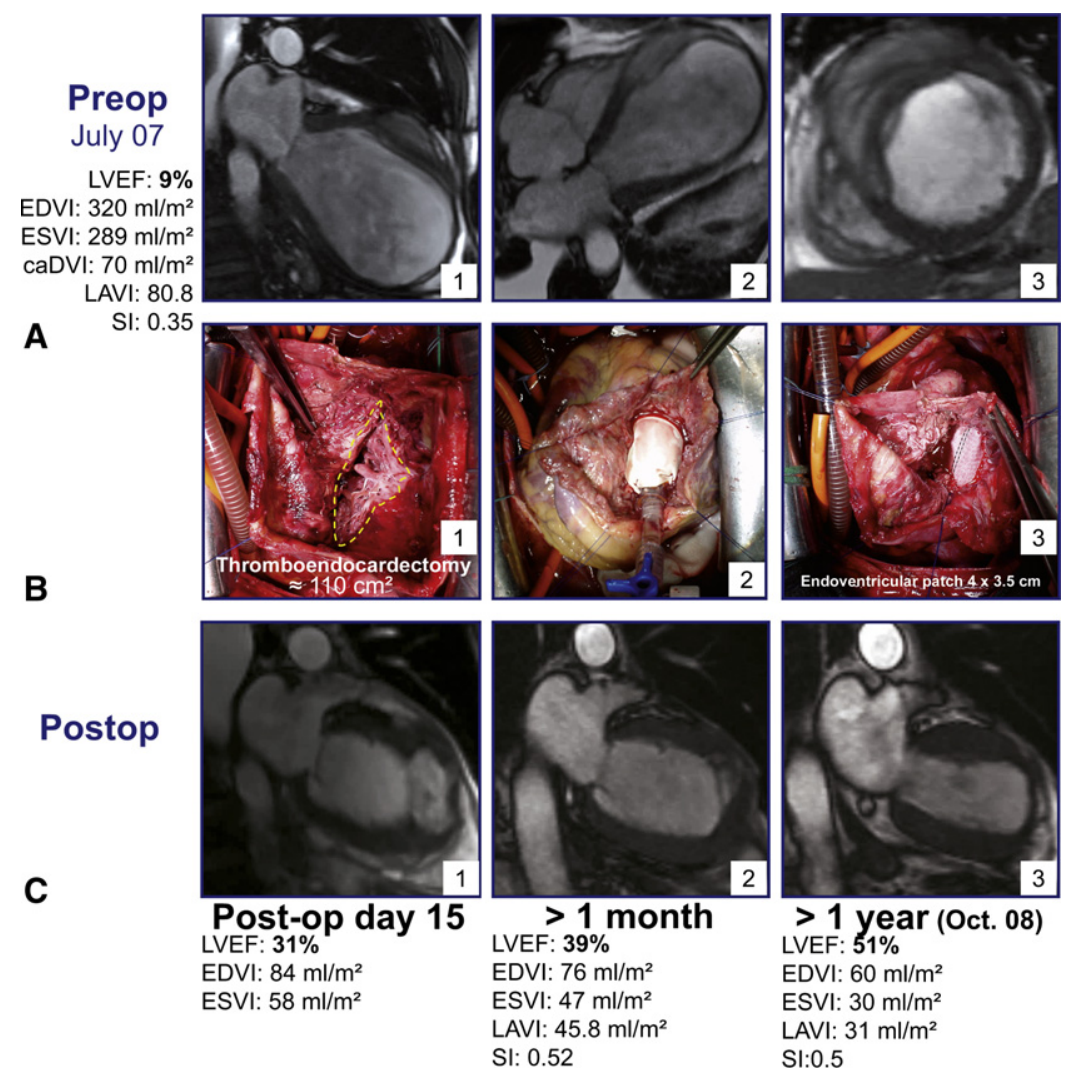

FIGURE 6. Giant aneurysm in a hopeless situation (bedridden; brain natriuretic peptide $=4,421$ ): heart replacement versus left ventricular reconstruction? Contractile area diastolic volume index $(c a D V I)$ of $70 \mathrm{~mL} / \mathrm{m}^{2}$. Al, Preoperative 2-chamber view with a sphericity index (SI) of 0.35 . A2, Four-chamber view. $A 3$, Short-axis view. B1, "Contractility trail" after thromboendocardectomy $\left(110 \mathrm{~cm}^{2}\right) . B 2$, Balloon sizing $(90 \mathrm{~mL})$. B3, Rebuilt contractile left ventricular cavity with exclusion of the anterior wall, four fifths of the septum, half of the posterior wall, and one third of the lateral wall by a $10 \mathrm{~cm}^{2}$ patch. $C 1$, Twochamber view at day 15. Excluded left ventricular chamber still visible. $C 2$, Two-chamber view at 1 month. End-diastolic volume index (EDVI; $76 \mathrm{~mL})$ is close to the preoperative caDVI $(70 \mathrm{~mL})$ with an SI of 0.52. C3, Two-chamber view at 1 year with an SI of 0.50. LVEF, Left ventricular ejection fraction; ESVI, end-systolic volume index; LAVI, left atrial volume index. 
We thank Professor Eugene Grossi, New York University School of Medicine, for the revision and reorganization of the manuscript and Dr Raluca Trifanescu, Carol Davila University of Medicine and Pharmacy, Bucharest, Romania, for the statistical analysis.

\section{References}

1. Klein MD, Herman MV, Gorlin R. A hemodynamic study of left ventricular aneurysm. Circulation. 1967;35:614-30.

2. McKay RG, Pfeffer MA, Pasternak RC, et al. Left ventricular remodeling after myocardial infarction: a corollary to infarct expansion. Circulation. 1986;74: 693-702.

3. Chareonthaitawee P, Christian TF, Hirose K, Gibbons RJ, Rumberger JA. Relation of initial infarct size to extent of left ventricular remodeling in the year after acute myocardial infarction. J Am Coll Cardiol. 1995;25:567-73.

4. Antoniucci D, Valenti R, Migliorini A, et al. Direct infarct artery stenting without predilation and no-reflow in patients with acute myocardial infarction. Am Heart J. 2001;142:684-90.

5. Gaudron P, Eilles C, Kugler I, Ertl G. Progressive left ventricular dysfunction and remodeling after myocardial infarction. Potential mechanisms and early predictors. Circulation. 1993;87:755-63.

6. Sheehan FH, Bolson EL, Dodge HT, Mathey DG, Schofer J, Woo HW. Advantages and applications of the centerline method for characterizing regional ventricular function. Circulation. 1986;74:293-305.

7. Metra M, Ponikowski P, Dickstein K, et al. Advanced chronic heart failure: A position statement from the Study Group on Advanced Heart Failure of the Heart Failure Association of the European Society of Cardiology. Eur J Heart Fail. 2007;9:684-94.

8. Yellon DM, Hausenloy DJ. Myocardial reperfusion injury. N Engl J Med. 2007; 357:1121-35.

9. Schinkel AFL, Poldermans D, Rizzello V, et al. Why do patients with ischemic cardiomyopathy and a substantial amount of viable myocardium not always recover in function after revascularization? J Thorac Cardiovasc Surg. 2004;127:385-90.

10. Dor V, Kreitmann P, Jourdan J, Acar C, Saab M, Coste P. Interest of physiological closure (circumferential plasty on contractile areas) of left ventricle after resection and endocardectomy for aneurysm of akinetic zone comparison with classical technique about a series of 209 left ventricular resections [abstract]. J Cardiovasc Surg. 1985;26.

11. Abhayaratna WP, Seward JB, Appleton CP, et al. Left atrial size: physiologic determinants and clinical applications. J Am Coll Cardiol. 2006;47:2357-63.

12. Bellenger NG, Burgess MI, Ray SG, et al. Comparison of left ventricular ejection fraction and volumes in heart failure by echocardiography, radionuclide ventriculography and cardiovascular magnetic resonance; are they interchangeable? Eur Heart J. 2000;21:1387-96.

13. Grigioni F, Enriquez-Sarano M, Zehr KJ, Bailey KR, Tajik AJ. Ischemic mitral regurgitation: long-term outcome and prognostic implications with quantitative Doppler assessment. Circulation. 2001;103:1759-64.

14. Josephson ME, Harken AH, Horowitz LN. Endocardial excision: a new surgical technique for the treatment of recurrent ventricular tachycardia. Circulation. 1979;60:1430-9.

15. Dor V, Sabatier M, Montiglio F, Rossi P, Toso A, Di Donato M. Results of nonguided subtotal endocardiectomy associated with left ventricular reconstruction in patients with ischemic ventricular arrhythmias. J Thorac Cardiovasc Surg. 1994;107:1301-8.

16. Dor V, Sabatier M, Montiglio F, Coste P, Di Donato M. Endoventricular patch reconstruction in large ischemic wall-motion abnormalities. J Card Surg. 1999;14:46-52.

17. Dor V, Sabatier M, Di Donato M, Maioli M, Toso A, Montiglio F. Late hemodynamic results after left ventricular patch repair associated with coronary grafting in patients with postinfarction akinetic or dyskinetic aneurysm of the left ventricle. J Thorac Cardiovasc Surg. 1995;110:1291-301.

18. Menicanti L, Castelvecchio S, Ranucci M, et al. Surgical therapy for ischemic heart failure: single-center experience with surgical anterior ventricular restoration. J Thorac Cardiovasc Surg. 2007;134:433-41.

19. Bogaert J, Maes A, Van de Werf F, et al. Functional recovery of subepicardial myocardial tissue in transmural myocardial infarction after successful reperfusion: an important contribution to the improvement of regional and global left ventricular function. Circulation. 1999;99:36-43.

20. Bax JJ, Schinkel AF, Boersma E, et al. Extensive left ventricular remodeling does not allow viable myocardium to improve in left ventricular ejection fraction after revascularization and is associated with worse long-term prognosis. Circulation. 2004;110S(suppl II):II18-22.
21. Di Donato M, Sabatier M, Toso A, et al. Regional myocardial performance of non-ischaemic zones remote from anterior wall left ventricular aneurysm. Effects of aneurysmectomy. Eur Heart J. 1995;16:1285-92.

22. Di Donato M, Toso A, Dor V, et al. Surgical ventricular restoration improves mechanical intraventricular dyssynchrony in ischemic cardiomyopathy. Circulation. 2004; 109:2536-43.

23. Dor V, Saab M, Coste P, Kornaszewska M, Montiglio F. Left ventricular aneurysm: a new surgical approach. Thorac Cardiovasc Surg. 1989;37:11-9.

24. Salati M, Paje A, Di Biasi P, Fundaro P, Cialfi A, Santoli C. Severe diastolic dysfunction after endoventriculoplasty. J Thorac Cardiovasc Surg. 1995; 109:694-701.

25. Kokaji K, Okamoto M, Hotoda K. Atrophic degeneration and loss of myocytes of residual left ventricular myocardium after Dor operation for ischemic cardiomyopathy associated with left ventricular remodeling. Jpn J Thorac Cardiovasc Surg. 2003;51:634-7.

26. Jones RH, Velazquez EJ, Michler RE, et al. Coronary bypass surgery with or without surgical ventricular reconstruction. N Engl J Med. 2009;360:1705-17.

27. White HD, Norris RM, Brown MA, Brandt PW, Whitlock RM, Wild CJ. Left ventricular end-systolic volume as the major determinant of survival after recovery from myocardial infarction. Circulation. 1987;76:44-51.

28. Cooley DA, Collins HA, Morris GC Jr, Chapman DW. Ventricular aneurysm after myocardial infarction; surgical excision with use of temporary cardiopulmonary bypass. JAMA. 1958; 167:557-60.

29. Stoney WS, Alford WC Jr, Burrus GR, Thomas CS Jr. Repair of anteroseptal ventricular aneurysm. Ann Thorac Surg. 1973;15:394-404.

30. Froehlich RT, Falsetti HL, Doty DB, Marcus ML. Prospective study of surgery for left ventricular aneurysm. Am J Cardiol. 1980;45:923-31.

31. Buckberg GD, Athanasuleas CL. The STICH trial: misguided conclusions. J Thorac Cardiovasc Surg. 2009;138:1060-4.

32. Yoon DY, Smedira NG, Nowicki ER, et al. Decision support in surgical management of ischemic cardiomyopathy. J Thorac Cardiovasc Surg. 2010;139:283-93. e1-7.

33. Burkhoff D, Wechsler AS. Surgical ventricular remodeling: a balancing act on systolic and diastolic properties. J Thorac Cardiovasc Surg. 2006;132:459-63.

34. Borger MA, Alam A, Murphy PM, Doenst T, David TE. Chronic ischemic mitral regurgitation: repair, replace or rethink? Ann Thorac Surg. 2006;81:1153-61.

35. Mihaljevic T, Lam BK, Rajeswaran J, et al. Impact of mitral valve annuloplasty combined with revascularization in patients with functional ischemic mitral regurgitation. J Am Coll Cardiol. 2007;49:2191-201.

36. McGee EC, Gillinov AM, Blackstone EH, et al. Recurrent mitral regurgitation after annuloplasty for functional ischemic mitral regurgitation. J Thorac Cardiovasc Surg. 2004;128:916-24.

37. Lietz K, Long JW, Kfoury AG, et al. Outcomes of left ventricular assist device implantation as destination therapy in the post-REMATCH era: implications for patient selection. Circulation. 2007;116:497-505.

\section{Discussion}

Dr Robert H. Jones (Durham, NC). I thank the association for the invitation to begin this discussion, and I have nothing to disclose other than I am the principal investigator of the National Institutes of Health-funded STICH trial.

Dr Dor contributed to the initial planning of the STICH trial, insisted that the operation should be called ventricular reconstruction and not the Dor operation or restoration operation, and welcomed STICH surgeons into his institution for training. Today he described 274 patients with ventricular reconstruction treated concurrently with STICH enrollment and analyzed their outcomes by who was and was not STICH eligible. Fifty-seven percent of his patients were STICH eligible. STICH was designed as a broadly inclusive trial. Enrolled patients were those that responsible investigators and cardiac surgeons at each institution considered eligible based on their entire clinical picture. Therefore the combined zone of uncertain benefit about ventricular reconstruction in the minds of all participating cardiologists and cardiac surgeons largely determined the characteristics of the 1,000 patients randomized. Because STICH was based on clinical judgment for inclusion, specific exclusions were needed to 
constrain the extremes of inclusiveness so that the trial results could be generalized to a large and well-defined future population. For example, the protocol encouraged enrollment of patients with ongoing Canadian Cardiovascular Society class 3 or 4 angina undergoing intensive medical therapy but did prohibit enrollment of patients in cardiogenic shock on maximal support. The shock was not intended to suggest that patients with cardiac shock would not benefit from ventricular reconstruction surgery; it was needed for the integrity of the trial. It was considered unlikely that insufficient numbers of patients with cardiac shock would be enrolled to make a definitive subgroup conclusion about their benefit from ventricular surgery. However, should this high-risk population experience excess deaths in the ventricular reconstruction randomized treatment arm by statistical chance, these few patients might be contributing enough deaths to detract statistical power from the primary conclusion in the broad population of patients more commonly encountered in routine clinical practice.

However, this STICH protocol exclusion of ischemic shock need not prohibit use of the neutral results of the STICH trial for management decisions for patients with ICMs. For example, in a patient with cardiac shock, good coronary arteries for revascularization, and only mild anterior dyskinesia on cardiac catheterization, one might decide not to obtain a cardiac magnetic resonance (CMR) image to evaluate the need for adding ventricular reconstruction but would simply consider the ventriculogram and the echocardiographic findings adequate to simply revascularize that patient.

The STICH trial should not be considered as only informing the question of whether ventricular reconstruction should or should not be added to CABG for all patients with ICMs. The broader question the STICH trial informs is how much extra benefit might accrue from adding ventricular reconstruction to a specific patient who otherwise might be treated with CABG only.

Dr Dor, you have known the primary outcome of the STICH trial for more than a year. Most of the patients with ischemic HF you reported today could have been entered into the STICH trial. Has this neutral STICH result changed your equipoise for any of your health care diagnostic or treatment decisions for "STICHlike" patients, irrespective of whether they were technically STICH protocol eligible?

Dr Dor. Thank you. First of all, I want to thank you and to confirm that your trial, the STICH trial, was a biased trial because nearly one half of the patients in the IFV condition after infarction are excluded to not pollute the results of your trial. You confirmed this fact, and that is very important because I cannot understand why the scar was not assessed. In your trial there is not one indication about the size of the scar, its location, or its percentage, and in the other paper, it was never precise whether the ventricle was scarred. I agree totally that if a patient is totally ischemic with grade 4 Canadian Cardiovascular Association ischemia, you have to revascularize him or her. Nobody discussed the situation of when a patient has no more ischemia, a totally destroyed ventricle, and a large scar involving more than $50 \%$ of the ventricle: How can CABG alone improve this patient? That is clinically very ridiculous in a center in which we take care of this patient. You are out of reality.

The STICH trial is mathematically, for which we have statistics, irreproachable. It is a fantastic trial. But medically speaking, it is unfounded because more than half of the patients were excluded. You discuss the acute HF. How do you treat a ruptured septum not excluding the necrosed cavity?

Can you say to a cardiologist: Treat the patient without treating the cause and its consequence? It is impossible. Therefore the message that I want to be received by the community is that when you have a patient with an IFV, please make a complete and reliable assessment, and the use, in 2000's MRI, is mandatory. If the patient is ischemic, you can revascularize by means of PCI or surgical intervention; it is not a problem and up to you. But if the patient has a scarred ventricle, rebuild it, but correctly. Because in your trial, one thing was astonishing, that even if it is only assessed on one third of 1,000 patients, the decrease in end systolic volume was something like $16 \%$ (from 82 to $68 \mathrm{~mL} / \mathrm{m}^{2}$ ). That is a ridiculous result for reconstruction. Usually all our patients are below 60 $\mathrm{mL} / \mathrm{m}^{2}$, the threshold of prognosis for a patient. I was surprised by what was published this year at the American College that in the group of patients with large dilatation, $22 \%$ or $23 \% \mathrm{EF}$, the increase after surgical intervention was 2 points for revascularization and 5 points for ventricular reconstruction. What operation was done? I cannot understand what it is. Is it a new reconstruction of the ventricle? I showed the results of our whole identical series: the decrease of ESVI (from preoperative $95 \mathrm{~mL} / \mathrm{m}^{2}$ to postoperative $48 \mathrm{~mL} / \mathrm{m}^{2}$ ) reaches $50 \%$.

Therefore you confirmed the fact that you excluded severe patients to do not pollute your trial, and our presentation confirms the fact that the STICH trial is not reliable because patients with a scarred ventricle are not assessed or treated.

Dr Jones. I will respond briefly to permit others to join the discussion. The STICH trial was not designed to definitively answer the question of whether ventricular reconstruction should ever be done in patients with extensive scarring of the left ventricle. Cardiac surgeons identified patients for whom adding SVR to CABG would be ethical as long as the LVEF was 0.35 or less and dominant anterior LV dysfunction was present.

We then documented the best available baseline core laboratory measurement of global and regional dysfunction and ventricular size reported from the ECHO, SPECT, and CMR core laboratories without knowledge of the treatment assignment of the patient. The results to be published soon document a wide spectrum of ESVI and regional LV function in the 1,000 STICH patients. Moreover, the change in global LV function from baseline to 4 months after the operation will be reported based on the specific operation performed. These will be the first preoperative to postoperative LV volume-change data with results reported using data directly quantitated from images by study readers who could not have known which operation was performed. We also have radionuclide and CMR gadolinium viability measurements on a substantial number of these patients that are likely to provide additional insight about baseline characteristics of the STICH patients randomized to CABG with or without SVR.

The knowledge the STICH trial contributed about the value of ventricular reconstruction applies to a broad spectrum of CABGeligible patients with ICMs. Clinical outcomes showed no benefit of ventricular reconstruction throughout the entire range of clinical and cardiac function parameters and were not dependent on change in volume 4 months after the operation. Because 
preoperative to postoperative outcomes for the 2 operative strategies were the same for the end points of death, cardiac hospitalization, and physiological testing, this lack of harm from ventricular surgery indicates it would be safe to study other populations for whom a question of benefit for ventricular surgery added to CABG remains. The STICH trial provides valuable data that could be used to design future prospective observational or randomized studies in other ICM patient populations of interest.
Dr Dor. I will answer very quickly. I thank you to mention the neutral results of the STICH trial. Your conclusion must add as a conclusion that all the cases that were not treated by the STICH study team will be interesting for cardiologists. Second, regarding the volumes you mentioned, they are assessed by means of echocardiographic analysis, and again, in 2000's magnetic resonance is more reliable to assess the volume of the heart before and after repair.

I thank you for your comments and I thank the association. 


\section{9 patients after $\mathrm{PCl}$ for $\mathrm{AMI}$}

II.

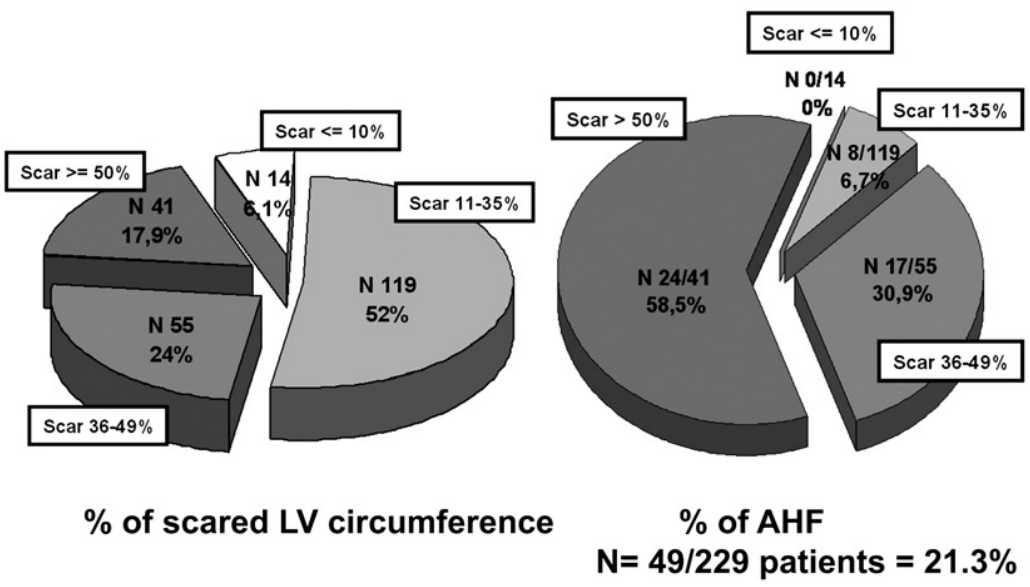

A

B

FIGURE E1. Linear relationship between infarct size/degree of advanced heart failure $(A H F)$ II in patients with percutaneous coronary intervention $(P C I)$ for coronary recanalization at the acute phase of myocardial infarction (AMI). A, Scar extension (percentage of left ventricular [LV] perimeter) in 229 patients. B, Degrees of advanced HF according to percentage of scar extension.

Day 12 post MI

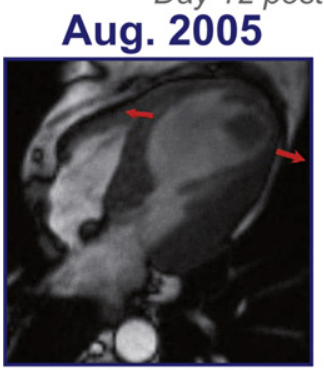

ESVI: $38 \mathrm{ml} / \mathrm{m}^{2}$

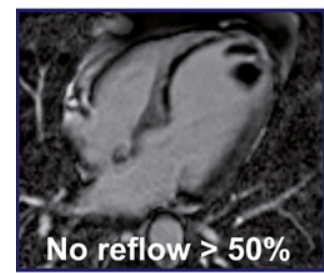

A
Nov. 2005

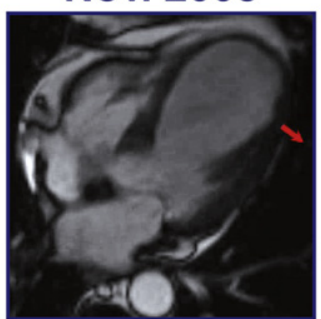

ESVI: $55 \mathrm{ml} / \mathrm{m}^{2}$
Dec. 2005

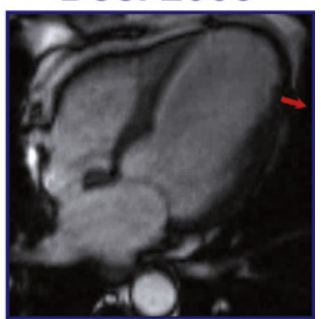

ESVI: $67 \mathrm{ml} / \mathrm{m}^{2}$

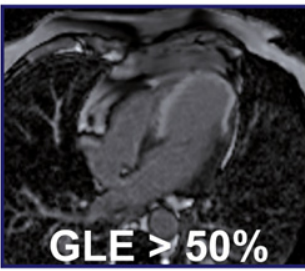

B

FIGURE E2. Mechanism of left ventricular dilatation in a 61-year-old patient with anterior myocardial infarction (MI) on August 5, 2005 (percutaneous coronary intervention + stent followed by congestive heart failure and intra-aortic balloon pumping). A, Immediately after myocardial infarction I, contractile myocardium surrounding the fresh necrosis (MVO) has a centripetal movement during systole (mitral leaflets closed) $=$ systolic eccentric motion (arrows; see Video 1). B, The definitive scar extension (gadolinium late enhancement [GLE]) of greater than $50 \%$ leads to progressive dilatation: in 4 months, the end-systolic volume index (ESVI) exceed the threshold of $60 \mathrm{~mL} / \mathrm{m}^{2}$ (see Videos 2 and 3). 


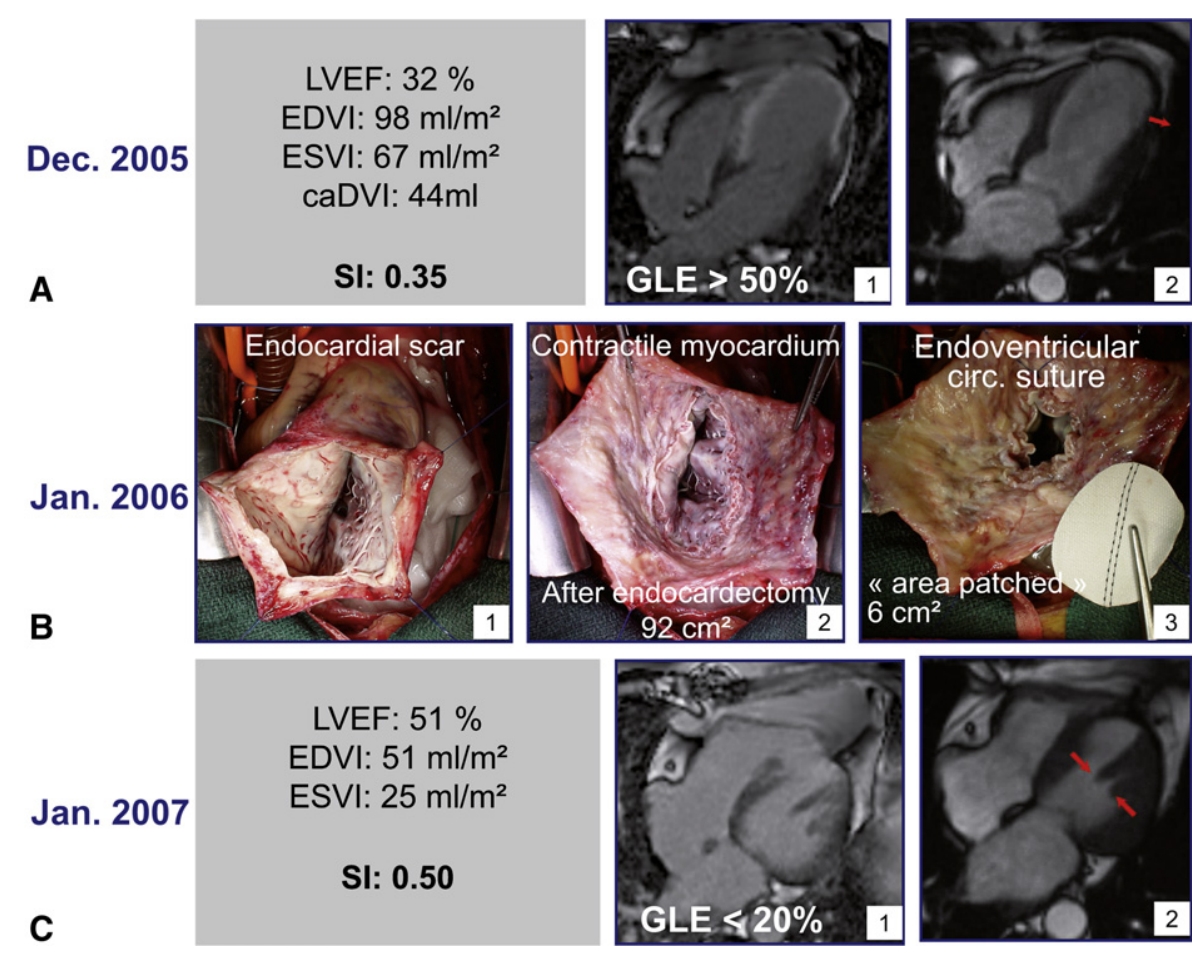

FIGURE E3. Reasons why left ventricular reconstruction $(L V R)$ is efficient (same patient as Figure E2). A1, Scar extension. Contractile area diastolic volume index (caDVI), $44 \mathrm{~mL} / \mathrm{m}^{2}$; sphericity index (SI), 0.35. A2, Eccentric systolic motion (arrows; see Video 4). B1, Endocardial scar. B2, Contractile myocardium after endocardectomy $\left(92 \mathrm{~cm}^{2}\right) . B 3$, Circular reorganization of contractile myocardium with a 6-cm ${ }^{2}$ patch. $C 1$, Postoperative gadolinium late enhancement $(G L E$; scar $<20 \%$ ). C2, Left ventricular cavity with restored systolic concentric contraction (arrows). End-systolic volume index (ESVI), $51 \mathrm{~mL}$ (close to theoretical preoperative caDVI); SI, 0.50 (Video 5). $L V E F$, Left ventricular ejection fraction; EDVI, end-diastolic volume index. 

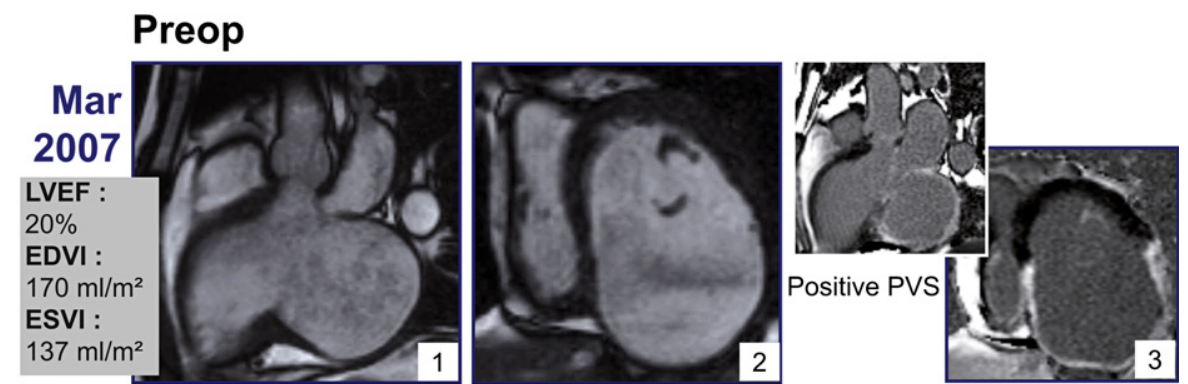

A

\section{Perop}
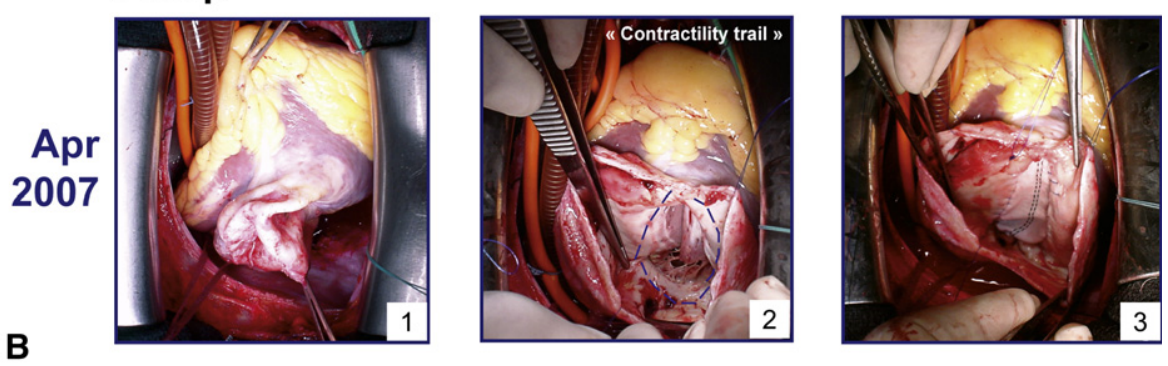

\section{Postop}

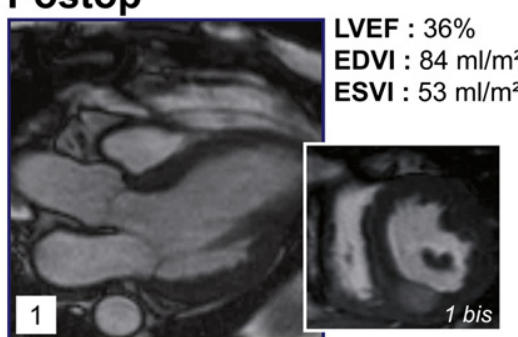

May 2007

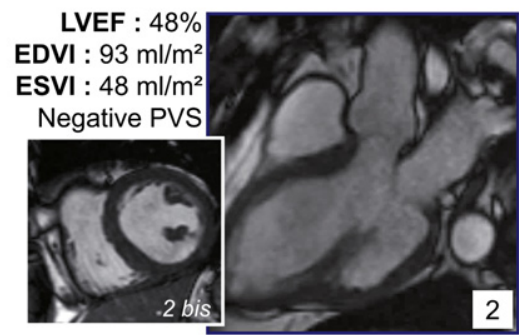

Apr 2008

FIGURE E4. Posterior aneurysm (56-year-old patient with congestive heart failure, class IV, plus cardiac arrest with ventricular tachycardia). A, Preoperative magnetic resonance imaging assessment. A1, Left ventricular outflow tract view (see video 6). A2, Short-axis view showing the eccentric systolic motion (arrows; see Video 7). A3, Gadolinium late enhancement on the aneurismal wall on the left ventricular outflow tract and 3 bis on short-axis view. PVS, Programmed ventricular stimulation. B, Perioperative view. B1, Posterior wall on an empty heart. B2, The "contractility trail" at the limit between the akinetic and kinetic walls. $B 3$, The triangular patch reapproximates the lateral and septal walls without mitral annular distortion. $C$, Postoperative magnetic resonance imaging assessment. $C 1$, Left ventricular outflow tract and 1 bis short-axis views at 1 month (see Videos 8 and 9). C2, Left ventricular outflow tract and 2 bis short-axis views at 1 year, showing clearly restoration of concentric systolic contraction (arrows; see Videos 10 and 11). LVEF, Left ventricular ejection fraction; EDVI, end-diastolic volume index; ESVI, end-systolic volume index. 


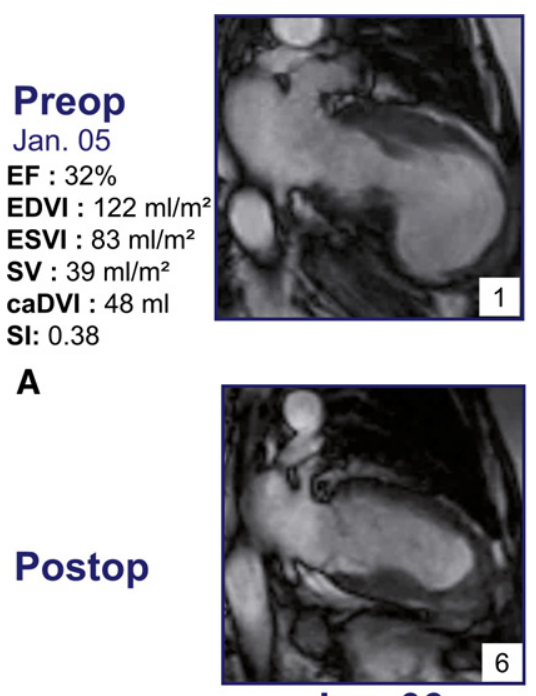

Jan. 06

EF: $56 \%$

EDVI: $40 \mathrm{ml} / \mathrm{m}^{2}$ ESVI: $17 \mathrm{ml} / \mathrm{m}^{2}$

B
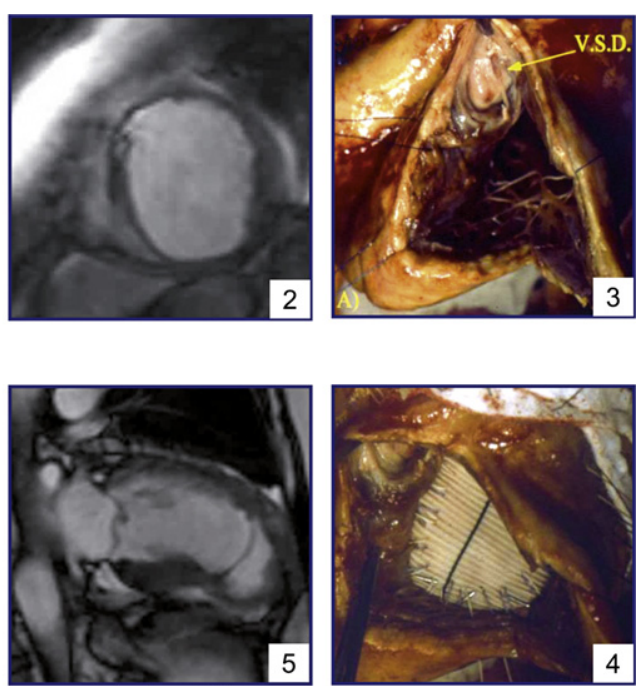

Feb. 05

EF: $43 \%$

SI : 0.23 EDVI: $41 \mathrm{ml} / \mathrm{m}^{2}$ SI : 0.27

ESVI: $23 \mathrm{ml} / \mathrm{m}^{2}$ SV: $18 \mathrm{ml}$

FIGURE E5. Anteroseptal rupture exclusion in a 76-year-old patient 1 month after left anterior descending coronary artery recanalization for myocardium infarction. A1, Two-chamber view of the necrotic aneurysm and eccentric systolic motion of the border zone. Contractile area diastolic volume index (caDVI), $48 \mathrm{~mL} / \mathrm{m}^{2}$; sphericity index (SI), 0.38 (see Video 12). A2, Short-axis view. The septal rupture is a dissection of the septum (see Video 13). A3, Septal rupture approached by means of anterior ventriculotomy. B4, Exclusion of ruptured septum from the rebuilt left ventricular cavity with patch inserted on normal myocardium. B5, Postoperative 2-chamber view at 1 month. The excluded necrotic area is still visible (see Video 14). B6, Normalization of the left ventricular aspect at 1 year. End-diastolic volume index (EDVI), $40 \mathrm{~mL}$ (close to the preoperative caDVI at $48 \mathrm{~mL}$ and restoration of concentric systolic contraction); SI, 0.23 (see Video 15). EF, Ejection fraction; ESVI, end-systolic volume index; VSD, ventricular septal defect. 